Fletcher, Thomas and Swain, Spencer

ORCID: https://orcid.org/0000-0002-2191-0041 (2016) Strangers of the north: South Asians, cricket and the culture of 'Yorkshireness'. Journal for Cultural Research, 20 (1). pp. 86-100.

Downloaded from: http://ray.yorksj.ac.uk/id/eprint/2456/

The version presented here may differ from the published version or version of record. If you intend to cite from the work you are advised to consult the publisher's version: https://doi.org/10.1080/14797585.2015.1134062

Research at York St John (RaY) is an institutional repository. It supports the principles of open access by making the research outputs of the University available in digital form. Copyright of the items stored in RaY reside with the authors and/or other copyright owners. Users may access full text items free of charge, and may download a copy for private study or non-commercial research. For further reuse terms, see licence terms governing individual outputs. Institutional Repository Policy Statement

\title{
RaY
}

Research at the University of York St John

For more information please contact RaY at ray@yorksj.ac.uk 


\section{Strangers of the north: South Asians, cricket and the culture of 'Yorkshireness'}

Thomas Fletcher and Spencer Swain, Leeds Beckett University

As a county, Yorkshire is what Wagg and Russell refer to as a 'cultural region': an imagined space, where culture is constructed, refined and articulated by a set of discursive relationships between local populations and a whole range of cultural forms. In this context however, culture is conceived as something which belongs to, and is only accessible by, certain groups of people. Our focus in this article is on the culture of Yorkshire cricket. Historically, Yorkshire cricket has been linked with white male privilege and some studies have shown that people within Yorkshire take a degree of pride in this. Consequently, the county and its cricket club have faced frequent accusations from minority ethnic communities of inveterate and institutionalised racism. Drawing upon Bauman's notion of 'liquid modernity', we argue that the processes of deregulation and individualisation championed by New Right policies have led to a divorce between power and politics, a corner stone of the old solid modern world. This in turn has led to an erosion of the state, causing individuals to navigate turbulent life projects which are consistently haunted by the spectres of fear and insecurity. Such an environment has caused cricket to be pushed further behind gated social spaces, in an attempt to maintain a semblance of 'community'.

Key words: British Asian, Cricket, Liquid Modernity, Northernness, Stranger, Yorkshire

\section{Introduction}

Over time, specific cultural groups become associated with specific spaces, and these spaces become marked as belonging to those groups. Carrington (2009) states how space and "the categories of legitimate presence or belonging to that space, [are] produced through a deeply racialised lens" (p.105) - what he refers to as 'topographies of race'. These "Topographies of race mark and define space itself shaping how different places come to be inscribed with racialised regimes of power that get enacted against and through particular bodies" (ibid.). Racialised tensions between White and

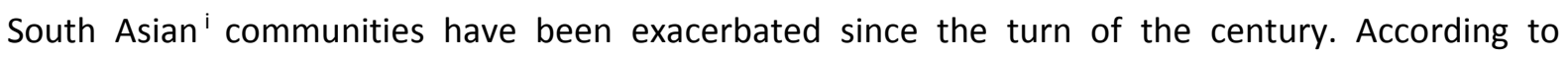
Sanderson and Thomas (2014) these have become symptomatic of a complex interplay across the country between territoriality and 'race'. They argue that how we understand race relations in northern England must be understood at the intersection of "complex urban settlement and resettlement, and the local configuration of the regions, towns and the populations surrounding" (Sanderson \& Thomas, 2014, p.1169).

Racialised tensions in northern England are not new. During the post Second World War and postcolonial periods Britain needed cheap labour to facilitate national recovery. Directly related to British colonial rule on the Indian subcontinent and Caribbean, families from these regions were encouraged to move to Britain to fulfil this need (Kalra 2000). Due to its burgeoning industries, Yorkshire was a popular settling place for South Asian migrants - particularly poor, mainly uneducated (Muslim) Mirpuris. Immigration to and settlement in some northern counties, such as Yorkshire, during this 
period was not straightforward. Some county identities, including 'Yorkshireness', are so strong that few people from other parts of the country, let alone migrant communities, can fully associate with local culture (Fletcher, 2011). In spite of the existence of migrant communities, historically, illustrations of northern England depict the region as a White monolith; concealing the region's ethnic diversity. Carrington (2009) notes how most regions have particular topographies of race that are manifest in complex ways. The north, and Yorkshire more specifically, is no different. The region has had a long association with racism, which has presented minority ethnic communities as 'Other' and anathema to Yorkshire culture (Fletcher, 2012).

This article will discuss the idea of 'Yorkshireness' as a predominantly inclusive, White working-class identity, whilst also considering how this identity has simultaneously excluded South Asian communities from certain cultural activities. We do this via the lens of cricket, given that cricket has historically featured as a microcosm for racial conflicts between both communities (Fletcher, 2011, 2012).

\section{Cricket and South Asian communities}

The Active People Survey (8) suggests that South Asian participation in sport (particularly amongst Pakistani and Bangladeshi women) falls consistently below other social groups (Hylton, Long, Fletcher \& Ormerod, 2015). A number of factors have been identified as contributing to this underrepresentation (cf. Long et al. 2009), including: low incomes; long working hours; religious observance; shortage of facilities in ethnic areas; language barriers and racism(s) (Hylton et al. 2015). It has also been suggested that there are cultural barriers to participation in sport; in particular with regards to diet and drinking (Fletcher \& Spracklen, 2014). Cricket is rather different. In 2014, 30\% of the estimated 908,000 people playing cricket over the age of 14 in England and Wales were of South Asian origin (ECB 2013). Moreover, since the late 1990s there has been a slow increase in the numbers of British born South Asians playing at county and international level and there have been various initiatives to engage racially diverse communities (Hylton et al. 2015).

Even in spite of this recent optimism we would warn that cricket does not (and has never) offered equal opportunities to all who have watched, played or followed it. Indeed, despite W.G. Grace's claim that cricket advances civilisation by promoting a common bond, binding together peoples of vastly different backgrounds (Sandiford 1998, p.22), to this day cricket operates strict symbolic boundaries; defining those who do, and equally, do not belong (Fletcher, 2015).

\section{Methodology}

Research for this article was conducted in Sheffield, South Yorkshire by Fletcher. It involved in-depth ethnographic fieldwork based on 21 semi-structured individual interviews, two focus group interviews and participant observation conducted with two different amateur cricket clubs. One of the clubs, 'Sutherland', was chosen because at the time of research, the club did not have a single minority ethnic member. The second club, 'Aylesworth' was chosen because the vast majority of its members were of South Asian descent. In total, 31 people were interviewed for the research: twelve identified as white and nineteen as either South or British Asian. The majority of the South Asian respondents were British-born, although a small number were migrants. A small minority had mixed white and South Asian parents. All were from a Pakistani Muslim background, though chose different descriptors to 
articulate this. The majority self-identified as either 'British Asian' or 'British Muslim'. Many used these descriptors interchangeably. A small, predominantly younger group cited no religious affiliation.

Interviews addressed topics including ethnic identities, belonging, community, religion, (anti) racism and ethnic privilege. They took place at a variety of locations, such as training grounds, players' homes, cafes/restaurants and bars. They varied in duration; from around 40 minutes to two and a half hours. Each interview was recorded via electronic Dictaphone and transcribed verbatim. All data from interviews and observations underwent inductive analysis and thematic 'coding'.

Fletcher is a cricketer himself and was known to the majority of respondents. The researcher was unquestionably an insider within this environment and this facilitated data collection. Respondents were recruited purposively via Fletcher's personal networks and subsequent referrals. This meant that identifying and recruiting participants was relatively straightforward. Fletcher's personal involvement in the sport also meant that he was already freely moving in this social world and understood many of the unique cultural practices and languages that pervade this leisure activity. However, as Fletcher A has noted elsewhere (Fletcher, 2014) a lack of cultural sensitivity and reflexivity on one's positionality in the field could have a number of negative consequences for research, including: distorting the voice and message of respondents; marginalising/silencing key perspectives; reinforcing the centrality of white ideologies and practices; whilst reifying 'whiteness' and assuming this perspective can best explain all number of experiences.

\section{Cricket, 'Yorkshireness' and modernity}

Sheffield is an ethnically diverse city, with around $19 \%$ of its population from minority ethnic groups (Sheffield City Council, 2014). The largest of those groups is the Pakistani community (4.3\%), but Sheffield also has large Black African Caribbean (3\%), Indian (1.3\%), Bangladeshi (0.6), Somali, Yemeni and Chinese communities (ibid.). Despite the White ethnic group decreasing in size, it is still the majority ethnic group.

Northern England, where Sheffield is located, arguably evokes a greater sense of identity than any other region of the country (Rawnsley, 2000). However, 'the north' is surrounded by social and cultural ambiguity as many of the characteristics of the north celebrated by northerners are mocked and rejected by those from other cultural regions (Russell, 2004). This is no more relevant than in discussions of the county of Yorkshire where, as we discuss below, there exists a very strong sense of regional identity which 'outsiders' rarely understand. For example, in September 2015, whilst preparing for a press conference in Leeds, British Prime Minister David Cameron was caught on microphone saying, "We just thought people in Yorkshire hated everyone else, we didn't realise they hated each other so much" (Pidd, 2015). While the comments came during an off-camera discussion about opportunity for devolution in Yorkshire, they were met with partisan criticism about his lack of understanding and respect for the county and its people.

Constructions of 'northernness' have emerged out of specific historical, social and economic conditions that distinguish it from 'southernness' (Frost, 2000). For Ehland (2007) northern England was the heartland of the Industrial Revolution and thus, associations that come most readily to mind are of industrial landscapes. The importance and productiveness of these landscapes are largely overshadowed by negative connotations - 'it's grim up north' - readily contrasted with the idyllic national character of the south. This juxtaposition has effectively positioned: 
The north and its inhabitants as curiosities which seem as exotic as they appear foreign. Set in the landscapes of the colonial imagination the northerner is turned into a passive object of the imperial gaze and becomes a stock figure loaded with cultural meaning in the mythologies of society. (Ehland, 2007, p.23)

According to Bramham and Wagg (2009) such mythologies of the north are outdated, as many of its towns and cities have entered a state of transformation. Bramham and Spink (2009) argue that urban populations have been affected by the structural reconfiguration of the world economies, bringing about an ideology that supports flexibility in employment, greater geographical mobility, increasing dispersals of ethnic groups, and the destabilising of local cultures and kinship networks. Despite the speed of social change within the region we argue that there remains what Raymond Williams called a local 'structure of feeling' that is established through the game of cricket and acts as a site where Yorkshire people can still express a fundamentalist notion of identity.

We argue that such an essentialised view of 'Yorkshire' and 'the north' can be unpacked through the historical period of modernity; an era where identity became freed from the constraints of ascription placed upon individuals by feudal estates (Bauman, 2001). This caused modernity to become "more dynamic than any previous type of social order" (Giddens \& Pierson, 1998, p.94). However, the transition from traditional society to modernity brought about a sense of disorientation for the populous, as the pace of social change made society unrecognisable. Such disorientation led to fear, which was fuelled by the increases in freedom afforded to people in their daily lives. As a consequence, human agents were left with a reduced sense of security, leaving many feeling alone and afraid of making decisions which had previously been ascribed by feudal faith structures. As Fromm ([1941] 1984) exemplified:

Freedom from the traditional bonds of medieval society, though giving the individual a new feeling of independence, at the same time made him feel alone and isolated, filled him with doubt and anxiety, and drove him into new submission and into a compulsive and irrational activity. (p.89)

The task of self-identification therefore, became centred on the logic of re-embedding oneself within a social framework, in essence "living true to kind (keeping up with the Joneses)" (Bauman, 2001, p.145). While traditional society provided individuals with a fixed identity from birth, citizens in the solid modern era had to manage their identity(ies). Such management involved displaying loyalty, through seeking membership to established social groups and their legislated codes of conduct.

Such an environment offered freedom (in principle), but in reality, many chose to conform to the comfort offered by security, found inside homogenised communities. Here loyalty was maintained by "following the pattern...not falling out of step, not deviating from the norm" (Ibid). Such models of conduct were created and legislated by the institutions of the state, chiefly by the politicians, philosophers and educators who "found chaos and set out to tame it and replace it with order" (Bauman, 1991, p.24). Such order was by its very nature artificial and therefore had to be endorsed around the concept of reason in order to delegitimise all opposition. This meant making identity and the subsequent behaviours associated with it, as sharp and clearly marked as possible, thus supressing and delegitimising all forms of Otherness. This provided a vital distinction between identities that were condoned as being at home within the group consciousness and identities that were condemned and cast away. As a result, security was provided through the way individuals, could band together under 
a shared notion of identity, helping to provide the foundations of cultural communities based around geographical locations, ethnicity, gender and class (Bauman, 2001). Thus, for those living in the 'north' and, we would argue, those involved with cricket, collective consciousness became centred around a homogenous and fixed White male identity which symbolised specific traits that individuals living in the region had to ascribe to in order to become accepted into the wider cultural consciousness.

Nayak (2003) refers usefully to the idea of 'learning to be local', whereby, in order to facilitate their integration and inclusion, visible minorities (i.e. 'non-white') must adapt their behaviours and movements to suit dominant cultural expectations - i.e. White expectations. These draw on a familiar schema of loyalty, origin and racial authenticity, so defining 'Yorkshireness' as an exclusive ethnicity. According to Hylton and Lawrence (2014) inherent to Nayak's understanding of 'race', racial identity and racialised processes is the notion of performativity. In simple terms, performativity is the perpetual repetition, reproduction and re-enactment of dominant discourses that serve to conceal the fictiveness of social identities. We would argue that similar identity performances remain at the heart of cricket cultures in Yorkshire.

To illustrate, many of the White respondents in this research expressed the same fixed view on what 'Northernness' represents and who embodies it.

I think ['northernness'] comes with certain values ... I think you are born into that. I don't think you can move to [the north] ... and then, in a couple of years say, "I'm a northerner". You can't learn it. (Jeff)

The majority of the White respondents referred in some way to the exclusionary nature of 'Yorkshireness'. Tony for example, believed that the people of Yorkshire are largely intolerant of difference:

Yorkshire people aren't that open-minded to difference ... Yorkshire is renowned for being a hard place to crack. Traditional mining communities where I would bet, for the first half of their lives, most people probably never saw an Asian person. So ... when they did start to interact with Asian people there probably was a bit of a, "who the fuck are you?" kind of attitude.

Tony was born outside of Yorkshire and came to Sheffield as a university student. He reflected on how he was able to overcome (or at least minimise) his differences, by embracing what he perceived as a fixed way of life.

Places like Yorkshire ... have that kind of proud history - especially in cricket - and the people within Yorkshire ... have quite strict criteria to being 'one of us'. I think anyone coming into these places had an uphill job to be accepted, but I think it's easier for some people. When I first came to Yorkshire, all that was different about me was my accent. I didn't look different and I didn't have any odd customs or anything like that. So I didn't have any trouble really. But in saying that ... it's important to act like the people in the place that you're living - so I was keen to take up the way of life of living in Yorkshire.

Tony is White, and clearly recognised the privileges this afforded him. His reference to adopting the way of life of Yorkshire people reflects well Nayak's (2003) notion of 'learning to be local'. Indeed, Savage et al. (2001) remind us that cultural spaces provide both places or 'habitats' for the possible 
development of common lifestyles and collective identities while, in the process, commanding opportunities for the cultivation of personal and social networks both within and across places of residence. Such places, according to Kirk (2000), become not just passive backdrops to social processes, but actively involved in the constitution and construction of social identities. As we examine throughout this article, access to these identities is contested. For instance, while the testimonies above suggest that 'Yorkshireness' is an ethnically exclusive identity, some of the British Asian respondents in this study questioned whether fixed readings of regional identities hold any analytical potential in contemporary society. Hamza Illyas for example, said:

I'm British, I'm Muslim, I'm Asian and I'm from Yorkshire. Does that mean I'm a Yorkshireman? I have a set of values that I have developed through my life ... and I'll tell you, they're all 'Yorkshire', but they're the same values that people live by in Kashmir. And these values are what make me, me. But which of those values makes me nonYorkshire?

Unquestionably, regional identities - in this case 'Yorkshireness' - are as much a state of mind, as they are a place (Hill and Williams, 1996). 'Yorkshireness', like 'Northernness', and any other 'region-ness', is a creation of the imagination, "a product of [invented] cultural traditions, assumptions and memories" (ibid, p.5); all of which vary over time and between places. It is how these traditions are maintained, and similarly, how they may be mobilised to exclude, that we now turn our attention to.

\section{'Northernness', strangers and the birth right policy}

We find Cohen's (1985) idea that communities are symbolically constructed particularly useful for establishing our theory around how cultural pastimes, including cricket, may be utilised by dominant communities as a means of demarcating boundaries of inclusion and exclusion. For Cohen (1985), whilst community continues to be both practically and ideologically significant to most people, its importance is not in what it means, or how it is defined, but in how it is used. As a consequence it is shared meanings and symbols that set communities apart, as it is the ability to decode these shared meanings that defines belonging. Therefore who belongs and who does not belong to a community is dependent on one's ability to interpret and understand these symbols. Access to the community is restricted to individuals able to adapt to an acceptable 'code'.

The issue of people belonging and not belonging to cultural communities influenced Georg Simmel (1950) who articulated his thoughts through the concept of 'the stranger'; a person who "comes today and stays tomorrow" (p.402). Simmel's (1950) primary concern was with understanding how the 'Other' can be interpreted within society, leading him to analyse issues of remoteness and proximity on one hand, as well as detachment and participation on the other. Alfred Schutz (1944) built upon the concept of the stranger as a marginalised member of the community, taking on the identity of the migrant or refugee who struggles for acceptance in the local community. He argued that the stranger finds her/himself in a situation where s/he becomes 'Othered' due to the fact that their presence is not valued, and their identity is not recognised, resulting in the individual being perceived with mistrust and caution.

Bauman (1997) builds upon this work, arguing that strangers have historically represented a site of contention, due to their propensity for rupturing the artificially designed homogeneity promoted by the institutions of modernity. Within British cultural politics there has been a tendency to exclude 
rather than incorporate alterity, resulting in the stranger becoming a symbol of disorder. As a consequence, the stranger had to be managed through two alternative yet complementary methods. The first, known as 'anthropophagic', devours strangers by transforming them into citizens of the state, making them indistinguishable from the host population. This became known as a strategy of assimilation, whereby difference became eradicated. The second strategy, referred to as 'anthropoemic', banishes strangers from the limits of the orderly world, stopping them communicating with those on the inside, through being exiled behind the walls of the ghetto, asylum, or 'no go area'. As a result "the stranger can never be part of the natives who are friends, and neither can he or she be part of the foreigners who are enemies and distant" (Robinson, 1992, p.174). They are instead forced to occupy a space in-between.

A good example of Othering in the context of Yorkshire cricket was Yorkshire County Cricket Club's (YCCC) birthright policy, which existed up until 1992 and restricted participation to those players born within the county's boundaries. Although the policy's strictness was never sacrosanct, it added to the perception that the club was inherently ethnocentric; particularly as, when the birthright policy was in effect, many of Yorkshire's ethnic minorities qualified to play for the club. Consequently, many have argued the policy was used as a means of asserting the club's White identity and, by implication, excluding ethnic minorities (Fletcher, 2012).

The White and British Asian respondents in this research held heavily contrasting views on the policy. The British Asian respondents believed the policy was exclusionary and indicative of the club's 'whiteness':

For me, that policy was racist ... It was biased against Asian people and, in many ways, is why I don't identify myself with YCCC. (Ali)

There were Asian people who were born in Yorkshire well before the policy was stopped. Why didn't any of them play for YCCC? I'll tell you why ... that policy wasn't about being Yorkshire-born, it was about people being white. (Inzy)

Such views on racism and exclusion have an impact off the cricket pitch too. Recently, Hylton et al. (2015) demonstrated how very few ethnic minorities support YCCC and even fewer attend live matches. They also identify that highly talented minority ethnic players are reticent about trialling for the club on the basis that, regardless of their abilities, they would not get selected (ibid.). Moreover, a recent investigation into the lack of South Asian cricket coaches documented how, among other things, YCCC's perceived 'Whites only' legacy deterred some South Asians from accessing coaching opportunities (Fletcher et al. 2014).

In contrast, White respondents were quick to defend YCCC and the birthright policy; preferring instead to emphasise how the policy was a celebration of regional identity:

I'd love to see that [birthright policy] back because the more people you get playing from outside the club the more you lose your identity and the less traditional values you keep ... I'm more traditional, I'd prefer to see proper Yorkshire lads representing Yorkshire [CCC]. (Rocco)

More generally, the majority of the White respondents believed the abolition of the policy was indicative of changing notions of regional identity and of a changing Yorkshire generally. Whilst some 
saw strength in these developments, others were nostalgic for the 'traditional' Yorkshire of the past. As Fletcher (2011) has argued elsewhere, "The imagined community of Yorkshire cricket is still 'bounded' by a northern, white masculinity, and those who embody these identities are keen to protect their heritage by denying many ethnic minorities access to the imagined community" (p.9). However, it must be understood that this defensiveness does not revive the community in a 'real' sense; the progressive decline of any stable basis for 'Yorkshireness' has removed it as a real source of solidarity (ibid.).

\section{Liquid modernity and the search for togetherness}

As the reality of a homogeneous notion of 'Yorkshireness' evaporates, and society falls under the influence of globalising forces that change the social fabric of the region through increased migration and de-industrialisation, this imagined sense of 'Yorkshireness' becomes problematised. We argue that cricket clubs form one of the bastions around which the ephemeral conditions effecting contemporary society become cast out of the psyche, and notions of cultural homogeneity can be rearticulated. This, we argue, helps individuals maintain a degree of security and stability; in essence providing a shelter from the rapidly changing environment 'outside'. An example of such a scenario can be seen in the way certain social groups have established ethnically uniformed teams and leagues to maintain levels of segregation through enforcing barriers based around symbolic notions of authenticity which facilitate belonging to both club and community (Fletcher \& Walle, 2015).

We use the theoretical lens of liquid modernity, articulated by Zygmunt Bauman (2000), to conceptualise these developments. Liquid modernity is symbolised by increased mobility, a paucity of stable state institutions, and the fluid nature of social life. Consequently, individuals living within liquid modernity become deprived of legislative frames of reference, meaning they have to make do with short term fragmented life projects. Such an environment is brought about by the separation of power and politics, which has led to a situation where the nation state is now devoid of the power it once wielded over territorial forces. This is because the social and economic processes of globalisation undermine 'simple modernity' and the idea of the ethnically homogenous nation state. These political and cultural dimensions which run in conjecture with globalisation have changed the relationship between local and global, as well as that of the domestic and foreign. The fear and confusion this instils reflects a situation whereby citizens in a society cannot live without the cooperation of their fellow comrades (Bauman, 2006).

This is seen in the way migrant communities often turn to 'familiar' sport and leisure activities when settling into new surroundings. Burdsey $(2009$, p.708) contends that the formation of Asian-specific sports teams needs to be contextualised within contemporary society both in the 'immediate postmigration phase' and the 'racial politics' that result from it. The emergence of ethnicity-specific teams and leagues in Yorkshire unsurprisingly coincided with the migration of different ethnic groups to the region, and for some, their existence reflected some of the ethnic and racial tensions facing these communities at the time. The Quaid-E-Azam league in Bradford for instance was established in 1981 with the specific purpose of providing South Asian communities (mainly Pakistani), who had been unable to access White teams, with opportunities.

Leagues like Quaid-E-Azam were established for the right reasons: to give Asians the chance to play. (Ali Khan) 
Similarly, the Khalifa league, which was established by Indian Gujarati Muslims aims to connect other members of the diaspora, who are dispersed throughout the UK.

So when you go to another town, we get to know who, the community which is there, who's there, how we're related and to be able to build that further through the medium of cricket. (Focus group respondent)

[S]ince the time of migration to the UK, obviously everyone went to different areas to be living ... So it [the league] was built on those grounds so that it will encourage people to know each other, to bring people together really. (Focus group respondent)

The significance of cricket to the overall migratory experience was affirmed by Aylesworth's Taz:

They [Pakistani Muslims] love to play cricket. I think a lot of them played cricket in Pakistan before they came over. Obviously, over there, the team was eleven Asians...eleven Pakistanis playing in a team. So maybe, it reminds them a little bit of 'back home'.

Thus, cricket represents normalcy post-migration, and given its cultural significance on the subcontinent, helps to maintain a wider diasporic consciousness. The origins and personalities of clubs, therefore, reflect the ensuing socio-economic and cultural context of the time.

Evidence indicates that a high number of British Asians are living in the poorest areas of Sheffield Sharrow, Burngreave and Darnall (Football Unites Racism Divides, N.D) - a pattern recreated elsewhere. According to Ratna (2009), many of the British Asians living in these areas would argue that "the supportive community and religious networks available to them in these neighbourhoods ensure their well-being in an otherwise alienating city" (p.174). Indeed, according to Phillips et al. (2007) some British Asians fear crossing from 'Asian' spaces into 'White' spaces of cities. As articulated by Ali Khan:

These areas were areas which were settled in through initial migration ... where it was felt safer to live together because of safety and community reasons. Asians, including Pakistanis are moving to the suburbs but the majority remain because of family connections, and community reasons.

In response to feelings of separation and marginalisation we argue that the leisure activity of cricket is used by many of the respondents in an effort to cement belonging, while also fostering a site of community and togetherness.

You do get those clusters, yeah. But it's only down to comfort. I've been the only Asian on a street or whatever, it felt awkward ... like people were looking at me funny, laughing at me. That's not good for self-esteem. I think now that there's a lot of Asians, you get a more family atmosphere you know. It's like being at home. (Immy)

Irrespective of having experienced racism from White people in the past some of the respondents denied the political dimension of Asian-specific teams and leagues. Instead, they emphasised how these spaces provide solidarity and a sense of family not offered elsewhere ${ }^{i i}$ : 
Playing with the lads is like a continuation of family for us. These two guys (pointing) live on the same street as me. So, we're living together and playing together. You don't get that type of friendship and solidarity playing with White guys because they don't seem to have those close family values. (Bobby)

No one ever told me I couldn't play in a mixed team. I know that I could have. It wouldn't be the same though. These lads are my mates. We're friends; not just team mates. No one in our team has to pretend who they are. It's like a brotherhood. (Rio)

Leisure plays a major role in developing the collective values of marginalised communities. We argue that it is through coming together in the realm of leisure that individuals find a sanctuary "by conforming (to) the expectations of others, by not being different, (alleviating) doubts about one's own identity...(and helping to provide) security" (Fromm, 1941[1984], p.219).

We believe that the construction of community is an attempt to create and mobilise particular kinds of social relations, but this cannot be achieved through symbols alone. If we fail to see boundary making as anything other than symbolic, we overlook the materiality of community as a lived cultural experience; that is, in terms of White domination, cultural racisms and exclusion. For example, a number of the White respondents were openly hostile to the concepts of 'Asian' and 'Asianness' and lamented how White people had to share cultural spaces and resources - including cricket - with those they perceived to be 'Other':

We [White people] were here first. How about they [South Asians] just fuck off. (Ron)

Whilst the other White respondents were less ferocious in their assessment they did demonstrate the belief that South Asian communities and their attendant 'Asianness' needed to be minimised, or at least, controlled. These findings are reflective of a recent study on young White and South Asian Muslim boys and girls in northern England (Sanderson \& Thomas, 2014) which employed research techniques based on word association where respondents were asked to list terms they associated with their ethnic 'Other'. Results demonstrated that the White group responded to the word 'Muslim' with a set of associations that expressed hostility. Similarly, reaction to the label 'multicultural' was met with negative connotations. Their findings reflect, as do ours, a tendency among some White communities to define 'Whiteness', 'Englishness' and, in this case 'Yorkshireness', in terms of their incompatibility with Asian and/or Muslim identities.

On discussing how ethnic tolerances in Yorkshire could be maximised, the majority of White respondents in this study said that the assimilation of South Asian communities was essential. John simply said that South Asians needed to "make the effort to fit in", whilst others were more essentialist; speaking in terms consistent with processes of de-racialisation:

I don't think they have to deny who they are or become someone else. They don't have to change their beliefs or anything like that ... That's just what they do. But there are ways that they can keep believing the things they believe, but still be English. It's important they be like us. (Tony)

I think there are a number of English people who are frustrated with them because they don't feel as if they should be here because they don't want to be like us. I think it would help if the English could see that they were trying or that they wanted to be like us; then 
I don't think there would be as much of a divide. But I think they are happy coming into this country, with the same traditions that they've always had and that's being Asian and wearing Asian clothes and doing Asian things. A lot of them don't try. (Graham)

Fletcher: Don't they have the right to ...?

I think it's a load of rubbish to be honest ... if you're coming into this country you've got to be seen as an English person by everyone else. (Graham)

The conversation above highlights the view held by many White British people that South Asian communities must deprioritise aspects of their ethnic and cultural identities in order to fit in. Hylton (2009) argues that when minority ethnic players are perceived to be unthreatening and their potential to be a 'dangerous other' is minimal, they effectively 'lose' their racial identities, thereby becoming more palatable in White spaces. This malleability of ethnic identities is well articulated by Hall (1995), in her study on British Sikhs, suggesting that "there's a time to act English and a time to act Indian". Central to this ideology, Hall argues, is the belief that individuals from minority ethnic communities are capable of cultural change and are encouraged to "reject their inferior cultures and become absorbed as much as possible into the superior culture of the British" (p.250). Therefore, if individuals choose not to assimilate, and instead assert their cultural distinctiveness, the logic goes that "they have only themselves to blame for their inferior status" (ibid.). In the context of this research the White respondents had constructed the sport of cricket as 'their' space; a space for White Yorkshire people.

\section{Discussion}

Racialised meanings and demarcations of Otherness are mapped and inscribed onto particular sporting spaces which, through their use and (re)imagination, interpellate particular bodies as (in)organic members, and facilitate claims as to who belongs and who does not (adapted from Burdsey, 2011, pp.540-541). Taking this into account, the minority ethnic cricket player, coach, spectator or administrator might therefore be conceptualised as a 'stranger'. As we have argued, according to Simmel, the stranger is recognised as someone who has been here before, and because of previous engagements and the manner in which this space is delineated and controlled, they are already recognised as not belonging, as being out of place (see Ahmed, 2000). As we have demonstrated, for this to occur, cricket must be continually demarcated as a space where those who are not strange, i.e. white British communities, do belong.

In this article we have argued that as society fragments, individuals become frightened and uncertain, as the task of navigating the liquid modern world becomes an individualised task. Beck (1992) argues that as a consequence of individualisation, human beings now "...regard themselves as organisers of their own circles of contacts and relationships" (p.97). However, the key problem for individuals living within such a liquefied world is that these "connections tend to be too shallow and brief to condense into bonds" (Bauman, 2003, p.62); leaving people with a growing sense of insecurity and isolation, a feeling which they try to overcome through belonging to stable groups or communities - in this case, cricket teams.

Erich Fromm ([1941]1984) warned that the breakdown of old securities, namely communities and families, would lead to increasing levels of fear and anxiety within Western societies. This, he argued, 
could lead to people finding communion and belonging in belief systems and social movements that bind them to ever new and more deceiving forms of submission and domination. This is because the very essence of human nature is centred on the need to be related to the world outside of one's self. Such relatedness allows individuals to become associated to the most basic pattern of social life, which many see as being preferable to being totally alone. Whilst Fromm was clearly not thinking about the interactions between White and South Asian communities who play cricket in Yorkshire, his ideas continue to ring true in the everyday lives of many. For example, we see in this research a genuine desire for belonging. In many cases, the White respondents long for nostalgic visions of a homogenous (White) Yorkshire; knowing full well that their longings are hopeless. In contrast, the South Asian respondents demonstrate a longing to be accepted or at least, for those who acknowledge that true acceptance may never arrive, have some level of autonomy over their own existence. It is here that we witness the 'communion' and 'belonging' that Fromm refers to.

In Yorkshire and within the culture of Yorkshire cricket the view that South Asian communities must effectively change who they are in order to be integrated into White environments is hegemonic and is also cognisant of the hidden or coded nature of social inclusion (Burdsey, 2007). In the case of cricket in Yorkshire it is White men who take for granted the power of being white and this is reflected in their expectations of South Asian communities. Crucially, as King (2004) warns, "whiteness is a process by which white men [sic] cannot see the barriers facing [ethnic minority] players or how their actions contribute to the institutional forms of whiteness" (p.95). To gain inclusion in cricket, South Asians - like any other community - have to abide by its terms and conditions. However, these terms and conditions apply largely to reinforce the normalisation of 'whiteness' by whitewashing ethnic differences. Puwar (2004) explains that:

Whilst they (ethnic minorities) have to accept that skin colour is a permanent feature of their bodily appearance, they can change or slowly 'whitewash' bodily gestures, social interests, value systems and speech patterns ... Adherence to the norms and values of this hegemonic culture is almost a condition of entry. (p.15)

As was the case in Burdsey's (2007) and King's (2004) analyses of British Asian footballers and Black football coaches respectively, the South Asians involved in this research were acutely aware of White expectations towards their inclusion. Those who had represented predominantly White teams believed that inclusion relied on their ability to navigate their way through dominant codes of respectability. Some argued how emphasising commonalities, as opposed to downplaying cultural differences should be positioned at the heart of social inclusion, whilst others believed that the route to commonality was via dispelling differences. Both perspectives suggest that culturally and racially oppressed individuals may adopt certain behavioural strategies to 'adapt' their ethnicities to optimise their chances of inclusion in White dominated spaces. Crucially though, whilst some respondents were able and willing to learn and act 'local', there were others who, for a variety of reasons education and profession amongst them - continue to experience difficulty adapting themselves to be within a degree of White acceptability. Moreover, not all are willing to adapt/assimilate. Instead, when faced with White cultural racisms their search for togetherness may be most readily achievable when among other South Asians. Therefore, the sport of cricket, especially cricket in northern regions of the UK, where white racisms remain pervasive, continues to be a valid social milieu for understanding - and challenge - racialised tensions and exclusions. 


\section{References}

Ahmed, S. (2000) Strange encounters: Embodied Others in post-coloniality. London: Routledge.

Bauman, Z. (1991). Modernity and Ambivalence. Ithaca, N.Y: Cornell University Press.

Bauman, Z. (1997). Postmodernity and its Discontents. New York: New York University Press.

Bauman, Z. (2000). Liquid Modernity. Cambridge: Polity.

Bauman, Z. (2001). The Individualized Society. Cambridge: Polity.

Bauman, Z. (2006). Liquid Fear. Cambridge: Polity.

Beck, U. (1992). Risk Society: Towards a New Modernity. London: Sage.

Bramham, P., \& Wagg, S. (2009) Introduction. In P. Bramham \& S. Wagg (eds) Sport, Leisure and Culture in the Postmodern City (pp. 1-8). Surrey: Palgrave.

Bramham, P., \& Spink, J. (2009) Leeds - Becoming the postmodern city. In P. Bramham \& S. Wagg (eds) Sport, Leisure and Culture in the Postmodern City (pp. 9-32). Surrey: Palgrave.

Burdsey, D. (2007) British Asians and football. London: Routledge.

Burdsey, D. (2009) Forgotten fields? Centralizing the experiences of minority ethnic men's football clubs in England. Soccer \& Society, 10(6), 704-721.

Burdsey, D. (2011) Strangers on the shore? Racialised representation, identity and in/visibilities of whiteness at the English seaside, Cultural Sociology, 5, 537-552.

Carrington, B. (2009) Leeds and the topographies of race: In six scenes. In P. Bramham \& S. Wagg (eds) Sport, Leisure and Culture in the Postmodern City (pp.99-128). Surrey: Palgrave.

Cohen, A. (1985) The Symbolic Construction of Community, London: Tavistock.

ECB. (2013). Participation [online] available from http://www.ecb.co.uk/development/get-intocricket/participation/ [accessed January 28, 2015].

Ehland, c. (2007) (ed.) Thinking Northern: Textures of Identity in the North of England. Amsterdam: Rodopi.

Fletcher, T. (2011) "Aye, but it were wasted on thee": 'Yorkshireness', cricket, ethnic identities, and the 'magical recovery of community'. Sociological Research Online, 16(4), available online from: http://www.socresonline.org.uk/16/4/5.html

Fletcher, T. (2012) "All Yorkshiremen are from Yorkshire, but some are more 'Yorkshire' than Others": British Asians and the myths of Yorkshire cricket. Sport in Society 15(2), 227-245. 
Fletcher, T. (2014) "Does he look like a Paki?" An exploration of 'whiteness', positionality and reflexivity in inter-racial sports research, Qualitative Research in Sport, Exercise and Health. 6(2), 244260.

Fletcher, T. (2015) Cricket, migration and diasporic communities. Identities: Global Studies in Culture and Power, 22(2), 141-153.

Fletcher, T., Piggott, D., North, J., Hylton, K., Gilbert, S., \& Norman, L. (2014) Exploring the barriers to South Asian cricket players' entry and progression in coaching. London: England and Wales Cricket Board.

Fletcher, T., \& Spracklen, K. (2014) "Cricket, Drinking and Exclusion of British Muslims?" Ethnic and Racial Studies. 37(8), 1310-1327.

Fletcher, T., \& Walle, T. (2015) Negotiating their right to play. Asian-identified cricket teams and leagues in Britain and Norway. Identities: Global Studies in Culture and Power, 22(2), 230-247.

Football Unites Racism Divides. (N.D) Sheffield's ethnic minority communities [online] available from www.furd.org/resources/Sheffields\%20ethnic\%20communities.doc [accessed May 28, 2015].

Fromm, E. (1984). The Fear of Freedom. London: ARK.

Frost, D. (2000) Ambiguous identities: constructing and de-constructing black and white 'Scouse' identities in twentieth century Liverpool. In N. Kirk (ed.) Northern identities: historical interpretations of "the north" and "northerness" (pp. 195-218). Brookfield: Ashgate.

Giddens, A., \& Pierson, C. (1998). Conversations With Anthony Giddens: Making Sense of Modernity. Cambridge: Polity.

Hall, K. (1995) 'There's a Time to Act English and a Time to Act Indian, in S. Stephens (ed.) Children and the Politics of Culture, Princeton: Princeton University Press.

Hill, J., \& Williams, J. (1996) Introduction, in J. Hill., \& J. Williams (eds) Sport and Identity in the North of England, Keele: Keele University Press.

Hylton, K. (2009) 'Race' and sport: Critical Race Theory, London: Routledge.

Hylton, K., \& Lawrence, S. (2014) Reading Ronaldo: contingent whiteness in the football media, Soccer \& Society, DOI: 10.1080/14660970.2014.963310.

Hylton, K., Long, J., Fletcher, T., \& Ormerod, N. (2015) Cricket and South Asian Communities. Leeds: Yorkshire Cricket Board.

Kalra, V.S. (2000) From Textile Mills to Taxi Ranks: Experiences of Migration, Labour and Social Change. Aldershot: Ashgate.

King, C. (2004) Offside Racism, Oxford: Berg.

Kirk, N. (2000) Constructions of 'The North' and 'Northernness'. In N. Kirk (ed.) Northern identities: historical interpretations of "the north" and "northerness". Brookfield: Ashgate. 
Nayak, A. (2003) Race, Place and Globalization: Youth Cultures in a Changing World, Oxford: Berg.

Phillips, D., Davis, C., \& Ratcliffe, P. (2007) British-Asian narratives of urban space. Transnational Institute of British Geography, 217-34.

Pidd, H. (2015) David Cameron wasn't rude about Yorkshire - he was right [online] available from http://www.theguardian.com/commentisfree/2015/sep/11/david-cameron-wasnt-rude-aboutyorkshire-he-was-right [accessed September 14, 2015].

Puwar, N. (2004) Space Invaders: Race, Gender and Bodies Out of Place, Oxford: Berg.

Ratna, A. (2009) "Off with their headscarves, on with their football kits?": Unveiling myths and exploring the identities of British-Muslim female football players. In P. Bramham and S. Wagg (eds) Sport, leisure and culture in the postmodern city (pp.171-188). Surrey: Ashgate.

Rawnsley, S. (2000) Constructing 'The North': space and a sense of place. In N. Kirk (ed.) Northern identities: historical interpretations of "the north" and "northerness". Brookfield: Ashgate.

Robinson, G. (1992). The Consequences of Alterity: Zygmunt Bauman's Modernity and Ambivalence. Thesis Eleven, 31(1), 168-178.

Russell, D. (2004) Looking North: Northern England and the national imagination. Manchester: University of Manchester Press.

Sanderson, P., \& Thomas, P. (2014) Troubling identities: race, place and positionality among young people in two towns in Northern England, Journal of Youth Studies, 17(9), 1168-1186.

Sandiford, K. A. P. (1998) England. In B. Stoddart., \& K. A. P. Sandiford (eds) The Imperial Game: Culture, Cricket and Society. Manchester: Manchester University Press.

Savage, M., Bagnall, G., \& Longhurst, B.L., (2001) Ordinary, ambivalent and defensive: class identities in the North-West of England, Sociology, 35, 875-892.

Sheffield City Council. (2014) Population and health of Sheffield [online] available from https://www.sheffield.gov.uk/your-city-council/sheffield-profile/population-and-health.html [accessed 28 May, 2015].

Schütz, A. (1944). 'The Stranger: An Essay in Social Psychology'. The American Journal of Sociology, 49(6), 499-507.

Simmel, G. (1950). The Sociology of Georg Simmel. New York: Free Press.

Wagg, S., \& Russell, D. (2010) Sporting heroes of the north. Newcastle Upon Tyne: Northumbria Press. 


\begin{abstract}
' We employ the term South Asian to describe individuals and communities with roots on the Indian subcontinent. The term British Asian is used to refer to those British citizens who trace their ancestry back to, or who themselves migrated from, the Indian subcontinent. It is employed as a dynamic category and its application has no firm boundaries.

ii For further discussion on the development and significance of Asian-specific leagues and teams see Fletcher and Walle (2015).
\end{abstract}

